\title{
What do climate change winners owe, and to whom?
}

\author{
Kian Mintz-Woo ${ }^{1, *}$ (iD and Justin Leroux ${ }^{2}$ (D) \\ ${ }^{1}$ Philosophy and Environmental Research Institute, University College Cork, 4 Elderwood, Cork, Ireland \\ and University Center for Human Values and Princeton School for Public and International Affairs, \\ Princeton University, Princeton, NJ, USA and ${ }^{2}$ Department of Applied Economics, HEC Montréal, 3000 \\ chemin de la Côte-Sainte-Catherine, Montreal, QC H3T 2A7, Canada, CIRANO and Centre de \\ recherche en éthique (CRÉ) \\ ${ }^{*}$ Corresponding author: Email: kian.mintz-woo@ucc.ie
}

(Received 12 April 2019; revised 12 October 2020; accepted 07 November 2020; first published online 23 February 2021)

\begin{abstract}
Climate ethics have been concerned with polluter pays, beneficiary pays and ability to pay principles, all of which consider climate change as a single negative externality. This paper considers it as a constellation of externalities, positive and negative, with different associated demands of justice. This is important because explicitly considering positive externalities has not to our knowledge been done in the climate ethics literature. Specifically, it is argued that those who enjoy passive gains from climate change owe gains not to the net losers, but to the emitters, just as the emitters owe compensation to the net losers for the negative externality. This is defended by appeal to theoretical virtues and to the social benefits of generating positive externalities, even when those positive externalities are coupled with far greater negative externalities. We call this the Polluter Pays, Then Receives ('PPTR', or 'Peter') Principle.
\end{abstract}

Keywords: climate change; climate justice; carbon tax; polluter pays principle; externality

\section{Introduction}

It is clear by now that human activity is responsible for climate change (IPCC 2014: SPM 1). The global rise in temperature, but also the increase in its variability, is already disrupting the living conditions of the current world population. This takes the form of reduced health (rise in respiratory illnesses and infectious diseases) (Watts et al. 2018); reduced safety (from extreme weather events); and reduced ecosystem services (more impact on storm buffers) (Nelson et al. 2013), to take only the anthropocentric view. ${ }^{1}$ The

\footnotetext{
${ }^{1} \mathrm{~A}$ recent survey of the morally relevant assumptions that go into calculating the cost of these damages was conducted by Fleurbaey et al. (2019).

( $)$ The Author(s), 2021. Published by Cambridge University Press. This is an Open Access article, distributed under the terms of the Creative Commons Attribution licence (http://creativecommons.org/licenses/by/4.0/), which permits unrestricted re-use, distribution, and reproduction in any medium, provided the original work is properly cited.
} 
impacts on non-human animals and potential intrinsic natural value would have to be added to this list. By all accounts, the worst is yet to come (cf. Mechler et al. 2019 , for discussion of impacts beyond our ability to adapt).

In addition, climate harm is unevenly distributed. But what makes the climate problem even worse from the perspective of justice is that the uneven distribution of harm is all but unrelated to the distribution of greenhouse gas (GHG) emissions that are responsible for it (Shue 1993, 2015). This has spurred a large literature on climate justice that has mobilized scholars from several disciplines, including philosophers (Gardiner 2004; Caney 2005; Gosseries and Meyer 2009; Gardiner 2011; Broome 2012; Meyer and Roser 2012; Kelleher 2017; Wallimann-Helmer et al. 2018) and economists (Billette de Villemeur and Leroux 2011; Fleurbaey and Zuber 2014; Dennig et al. 2015; Godard 2017).

While determining how to handle the plight of the victims of climate change is definitely a crucial issue, a complete treatment of the matter of climate justice must also explicitly account for the fact that there is growing evidence that some end up benefiting overall from the changing climate. This is at least the case over medium timescales, even in a context of increased emissions. By ignoring these benefits, we both open the possibility that a certain class of climate sceptic will think that theorists deny the heterogeneity of climate change and fail to recognize the theoretical complexity and interest that a full account of climate justice would require. ${ }^{2}$ Moreover, by considering these issues, and regardless of the practicality of the transfers we shall end up recommending, we introduce new arguments to guide political negotiations. ${ }^{3}$

Positive externalities are much smaller than the negative externalities from climate change, but their relative size is not a reason to ignore them. By (positive or negative) externality, we adopt the standard definition: (beneficial or harmful) effects of permissible actions on third parties that are themselves unable to affect (e.g. prevent) the actions. If emitters are to compensate those who have been harmed as a by-product of emissions, it seems fair to acknowledge the (more limited) benefits generated as by-products of the same emissions. Again, such beneficiaries are definitely the minority, mainly located in cold areas where growing seasons are short and where heating needs are high, but they exist (section 2). The claims in this essay are general enough to apply at any level but, for simplicity and concreteness, we primarily consider relevant winners at the national (potential winners include Canada, Russia and the UK, although it remains an open question whether any country as a whole is a net climate winner) and sectoral levels (potential sectoral winners in certain countries include agriculture, ocean transport and tourism).

\footnotetext{
${ }^{2}$ Rahmstorf (2004) calls those who underscore the possible positive consequences 'impact sceptics' and Poortinga et al. (2011: 1021) found this type of scepticism 'far more prevalent' than other types. By carefully discussing the limited and comparatively small positive climate effects, we may be able to take energy away from this kind of scepticism.

${ }^{3}$ Thanks to an anonymous reviewer for suggesting this pragmatic consideration.
} 
Because many individuals benefit from GHG emissions, directly or indirectly, it is important to make clear whom exactly we mean by 'net climate winners'. ${ }^{4}$ Indeed, while we use this typology for net climate winners, we believe this to be helpful for many areas of theorizing about beneficiaries, and hope that it opens up new dialectical space in discussions of beneficiaries. ${ }^{5}$ We identify four categories of benefits from GHG emissions:

1. The benefits from emitting GHGs, which emitters enjoy by externalizing the social cost of emissions. In fact it is the very reason why there are excessive emissions in the first place. We shall give emitters the moral standing of polluters because they are at the origin of the climate problem.

2. The indirect benefits from this cost externalization, enjoyed through bequests (by the heirs of emitters) or through being part of a firm that polluted under previous management. Although the beneficiaries are not themselves the emitters, it is possible to trace back their gains to the initial externalization of costs. As such, we argue that those gains should be considered in the same way as those of the emitters themselves. ${ }^{6}$

3. 'Passive gains', which are the gains one would obtain by pursuing the same policies despite the changed climate and economic environment; i.e., by not adapting their course of action. 'Passive net winners', the associated beneficiaries, can be those who gain merely through changes in supply or demand (e.g. extant air conditioner producers who benefit from the surge of demand associated with heatwaves) or whose production functions improve under climate change but not through any active policy (e.g. extant wine growers who find their grapes grow better or more cheaply). Note that passive gains are 'virtual': they are what would be gained if the beneficiary had not changed its practices.?

\footnotetext{
${ }^{4}$ Note that the relevant externalities need not be limited just to goods that are priced in markets. For instance, biodiversity losses may not be priced in markets (putting aside contingent valuation methods), but we could take the externalized costs of climate change to be some species damage at a value that reflects the resources needed to mitigate the harm. In particular, given a species harmed by negative externalities, we could take the damage to be the cost of helping save that species, e.g. the cost of setting aside a nature preserve and protecting the species.

${ }^{5}$ We happily agree with an anonymous reviewer that there is this broader applicability, which could also be applicable beyond climate contexts.

${ }^{6}$ The argument for this subsumption is as follows: on standard Polluter Pays Principle views, group agents can be held morally liable for pollution, and those group agents include individuals who have little or no decision-making power. For instance, the administrative assistant in an oil production facility benefits when the oil is sold and suffers if the facility is forced to transfer resources away, and we think this can be appropriate even when that assistant had no relevant decision-making capacity within the facility. Similar claims can be made when holding countries to be the polluters in terms of PPP, and carbon debts disadvantage taxpayers who had no control over national emissions strategies. If this is accepted, we believe a parallel case can be made that those who inherit gains from emissions as being subject to the same debts incurred by the initial externalization.

${ }^{7}$ Virtual costs or benefits are nothing new in economics, the most famous of which is undoubtedly the opportunity cost. It is defined as the value of the best alternative use of resources; i.e. the highest gain one would have obtained had they used their resources differently. The opportunity cost is generally used as a baseline to evaluate profitability, just like we shall use passive gains as a baseline above which to compute the next category of gains (i.e. 'active gains').
} 
4. Finally, in contrast to passive gains, are 'active gains', which are the benefits from changing one's course of action in response to climate change (e.g. by entering or exiting markets to seek new business opportunities). Examples of beneficiaries include firms that provide innovative adaptation solutions to counteract the negative impacts of a changing climate, or even individuals who take action to secure possible productivity gains brought about by a more hospitable climate in some areas (e.g. winemakers who develop businesses growing grapes where the terroir had been inhospitable before climate change). These are the gains enjoyed over and on top of the passive gains. We shall refer to the related beneficiaries as 'active net winners'.

To sum up roughly and to fix ideas for the rest of the article, we shall treat type-1 and type- 2 beneficiaries as 'the polluters'; type- 3 benefits are lucky gains, while type4 gains are deserved gains.

We can draw these distinctions formally: denote by $C$ and $C^{\prime}$ the old and new climates, respectively, and by $a$ and $a^{\prime}$ the actions taken by a decision-maker under the old and new climate, respectively. Finally, denote by $\pi$ the profitability of a given action in a given climate. An agent (an individual, or firm, or country, etc.) is a net winner if $\pi\left(a^{\prime}, C^{\prime}\right)-\pi(a, C)>0$. This net gain can be decomposed into two parts: $\pi\left(a^{\prime}, C^{\prime}\right)-\pi(a, C)=\pi\left(a^{\prime}, C^{\prime}\right)-\pi\left(a, C^{\prime}\right)+\left[\pi\left(a, C^{\prime}\right)-\pi(a, C)\right]$. The (counterfactual) bracketed gain, $\pi\left(a, C^{\prime}\right)-\pi(a, C)$, corresponds to the agent's passive/lucky gains whereas the gains $\pi\left(a^{\prime}, C^{\prime}\right)-\pi\left(a, C^{\prime}\right)$ represent the active/deserved gains.

Note that these categories of net winners are not mutually exclusive. For example, a farmer who is an heir to the fortune of an oil producer, whose fields have become more productive, and who has decided to switch to crops that are more suited to the new climate enjoys benefits of types 2,3 and 4 , simultaneously. ${ }^{9}$

What of these 'passive net winners'? Should they be left to enjoy the gains from the benefits brought about by a warmer climate even though they have no - or very little - responsibility for these changes and although climate change causes severe harm to many (section 3 )? Or does this passive betterment imbue them with a duty towards the rest of society? We argue for the novel claim that active net winners are entitled to their gains whereas passive winners are not: the latter owe their gains and not to the net losers, but to the emitters, in light of the positive externalities the emitters generate. We argue that these transfers are warranted provided that the emitters have compensated the net losers for the negative externalities they created.

As far as we know, the literature does not grapple with this issue. Although related, it is distinct from the more familiar question about who should bear the

\footnotetext{
${ }^{8}$ This is merely a shorthand term because active net winners also enjoy passive gains, the latter being virtual.

${ }^{9} \mathrm{Here}$ is a numerical example. Suppose the farmer has inherited $\$ 50 \mathrm{k}$ from the oil-producing activity of a relative. Suppose the increase in land productivity due to the new climate using the same crops and the same agricultural practices corresponds to a gain of $\$ 10 \mathrm{k} /$ year. Finally, suppose that the farmer has changed to crops better-suited to the new climate that now yield profits $\$ 25 \mathrm{k} /$ year higher than with the old crops prior to climate change. This farmer enjoys indirect benefits (type 2) from emissions to the tune of $\$ 50 \mathrm{k}$, passive gains (type 3) of $\$ 10 \mathrm{k} /$ year, and active gains (type 4 ) of $\$ 15 \mathrm{k} /$ year, the latter corresponding to the differential between the total net gains from farming and the passive gains.
} 
burdens and costs of climate change simpliciter (Caney 2005; Page 2008; Atkins 2018), where common answers point to the polluters ${ }^{10}$ (polluter pays principle, PPP) (Gardiner 2004), to the beneficiaries ${ }^{11}$ (beneficiary pays principle, BPP) (Meyer 2013; Butt 2014; Goodin and Barry 2014; Page and Pasternak 2014), and to those who have sufficient resources (ability to pay principle, APP) (Caney 2010). Our view differs significantly from these traditional climate justice principles. While those who defend PPP endorse our conclusions about the first category (and sometimes the second), the other categories are not part of this familiar view. While parts of our theory might appear similar to BPP (e.g. with respect to the second, third and fourth categories), there are two important points of divergence: (1) BPP theorists think the flows should go from the net winners to the net losers, not to the emitters, and (2) they do not make the distinction we do between active and passive net winners, something which will be integral to our view. Finally, this also differs from APP, since we are claiming that some should pay in light of their historical connection to externalities. In contrast to PPP, BPP and APP, we could call this view the PPTR (pronounced 'Peter') Principle, for 'Polluter Pays, Then Receives'.

Our concern is twofold: to incentivize efficient behaviour and to ensure the reparation of harm. PPP focuses on incentives and in reparation of harm (unless we are taking a simple Pigouvian interpretation), but it cannot handle cases of mixed externalities (some positive, some negative). By contrast, BPP focuses on reparation of harm, but is blind to incentives. Our PPTR principle allows for systematically addressing efficiency and reparation - with the latter being given priority - in settings with any permutation of externalities. It is not merely a convex combination of PPP and BPP since no combination of these principles justifies transfers from winners to emitters.

We then examine to whom this indebtedness should be directed (section 4). It may seem intuitive to ask of net winners to come to the aid of those that are harmed by the changing climate, whether current or future generations. But arriving at this conclusion requires first dealing with the asymmetry that this could entail: if the bulk of the climate justice literature views GHG emitters as responsible for climate harm and, therefore, liable to compensate climate sufferers, why should net winners not be symmetrically indebted towards GHG emitters, to the point of possibly rewarding them for the 'better' climate (in the eyes of net winners)?

We defend the view that the symmetry between gains and losses should be respected, with the implication that net winners are indebted to emitters, rather than to climate losers. Indeed, from the point of view of society, the emissions are the source of negative externalities but also of positive externalities. Hence, compensating the harmed is not the only relevant compensation: both 'passive'

\footnotetext{
${ }^{10} \mathrm{We}$ take the polluters referred to in the PPP literature to be those corresponding to our first category of gains, those gained from externalizing the social cost of emissions.

${ }^{11}$ We take the beneficiaries referred to in the BPP literature to be those corresponding to our second, third and fourth categories of gains. However, as BPP is often motivated by concerns of complicity, and our externality-based concerns are orthogonal to complicity, there might be differences here. Thanks to Avia Pasternak for conversation on this point. Along with one of our reviewers, she suggested that our arguments might support revisions or extensions to BPP instead of a rejection of it. We hope to take up this question in future work.
} 
net winners (those who passively gain from climate change) and net losers (those subject to net negative externalities) are morally required to compensate and receive compensation from emitters, respectively. Nevertheless, outside of the ideal case where emitters are willing and able to compensate net climate losers, we suggest relying on what we call a 'hierarchy of claims', which holds that compensating the harmed is of foremost importance. The implication is that, in non-ideal cases, (passive) net winners should compensate climate victims instead of rewarding emitters. Indeed, the hierarchy we propose also manifests itself among climate winners: we claim that what we call 'active' winners are entitled to their gains whereas 'passive' winners are not.

We then illustrate the implications of the view in a particular context, the Canadian federal system (section 5), where we examine two possible levels of application: by sectors of the economy (agriculture, tourism, etc.), or by province.

Finally, we conclude by arguing that this approach to net winners goes beyond the traditional three principles - PPP, BPP and APP - by drawing attention to the heterogeneous externalities involved in climate change (section 6).

\section{Net winners exist}

Mounting evidence suggests that some countries are experiencing gains from a changing climate to warmer temperatures or, at the very least, that this is true of some sectors of those countries over medium timescales. These countries are generally the ones with colder climates, such as Canada, Russia and the UK. While this evidence is meant to motivate the project, we are not committed to any of these particular actors actually being net winners. We wish to consider the normative situation where there are net winners, whosoever they ultimately are.

An alternative way of saying the same thing is that our claims are conditional on there being net winners from climate change. However, climate change itself is of course unnecessary to generate the kind of problem that we are concerned with in this paper. In general, all that is needed is (a) an agent, who acts or enacts policies which (b) generate positive and negative externalities. We can narrow the range of problems down further to those, like climate change, where the negative externalities are far larger in magnitude than the positive externalities, but that is not necessary. In short, the claims in this paper are conditional on a problem satisfying these two conditions, which we believe are satisfied in the case of climate change.

First, we provide evidence for the existence of net winners of the morally relevant type (subsection 2.1). Next, we offer both a couple of clarifications and some guiding intuitions behind our project (subsection 2.2).

\subsection{Evidence about net winners}

The expected climate gains are of various natures; our purpose in this subsection is to introduce a few indicative data. According to the IPCC, although 'negative impacts of climate change on crop yields have been more common than positive impacts (high confidence)' (2014: SPM 1.3.2) '[ $t$ ] here is also high confidence that warming has benefitted crop production in some high-latitude regions, such as northeast China or the UK' (also cf. Jaggard et al. 2007; Tchebakova et al. 2011; Gregory and 
Marshall 2012). Similarly, Arctic economies like Greenland's stand to gain from more productive cod and mackerel resources in a warming world (Kjesbu et al. 2014; Fossheim et al. 2015; Jansen et al. 2016). Broadly speaking, habitats towards the poles become more accommodating for various species as the climate warms (of course the converse is broadly true for habitats closer to the equator) (e.g. Poloczanska et al. 2013).

But gains can be felt outside of agriculture and wildlife as well. Longer summers boost the tourism industry in Arctic and polar regions (Buckley 2015). At the same time, less rigorous winters provide 'reduced requirement for indoor heating and a reduction in cold weather related deaths' in the UK (Vardoulakis and Heaviside 2012: 109). Finally, an overall more moderate climate may even increase productivity in Russia and Canada (Burke et al. 2015; Dellink et al. 2019), as well as facilitate oceanic trade due to an ice-free Northwest Passage between the Atlantic and Pacific oceans (Stroeve et al. 2008). Generally speaking, Dellink et al. (2019) find that of 25 regions modelled to 2060, two are predicted to be net winners from climate change: Canada and Russia (with Japan having roughly neutral expected net effects). ${ }^{12}$

\subsection{The externalities argument}

It is worth explicating that we are assuming the initial externalizing actions in question emitting GHGs - are permissible (i.e. neither required nor impermissible). If it were straightforwardly morally wrong to perform the action associated with the externalities in a given instance, it is plausible that society should provide no incentive to perform the action. We are not committed to this claim, but we do assume that the actions under consideration are permissible. What is morally impermissible, we claim, is generating externalities while not internalizing them.

It is also important to note that we consider this question in isolation from background injustices or antecedent distributions (i.e. we are considering changes from the status quo, not evaluating absolute outcomes). We see two reasons for this. First, we want to separate the descriptive statement that net winners (may) exist from the evaluative questions about how they came to exist. There may well be background injustices that led to these winners, but trying to untangle these would overly complicate the analysis. We believe that introducing more complexity can be done at a later stage, perhaps leading to principles with more conditions or caveats. Second, on the reverse side of the previous point, we are intending to determine what moral obligations may arise merely in light of climate net winners (losers) or, more generally, in light of different distributions of positive (negative) externalities. By focusing directly on one morally interesting phenomenon, we believe we can understand it more clearly.

\footnotetext{
${ }^{12}$ However, at smaller scales, such as sectoral or subnational, there would likely be other net winners, as Dellink et al. (2019) also discuss: net winners may be in other countries with similar climate conditions, but these are hidden in larger regional groups; for instance the Other OECD EU region covers both Scandinavian and Mediterranean countries. Minor benefits from climate change may also arise in other regions, like agriculture in Chile (where positive impacts on fruit and vegetables outweigh negative impacts on wheat).
} 
This is just to say that we are assuming that there is a special morally interesting question with respect to these net winners and we want to examine what the answer to such a question would be.

The motivation for our answer comes from two intuitions. The first is the intuition that those who do not face all the effects of their actions will, insofar as they are responsive to incentives, fail to act in ways that are best for society. The second is the intuition that, in remedying actions which generate externalities there should be transfers that, to the greatest practical extent possible, correct the incentives with respect to these externalities. In the longterm, these incentives will encourage better decision-making. Our view is that these straightforward intuitions have surprisingly broad implications.

The justification for the first intuition comes from the study of externalities. If there are costs (negative externalities) or benefits (positive externalities) which accrue without being accounted for (internalized) in the agent's decision-making, the agent will fail to act in ways that overall best benefit society. In the negative externality case, this is because there will be extra harms that are not counted and make the action less choiceworthy than the agent takes it to be; in the positive externality case, this is because there will be extra benefits that are not counted and make the action more choiceworthy than the agent takes it to be.

This leads to the second intuition. In order to address these externalities, we want there to be transfers that correct these incentives going forward. In some ways, this is a familiar claim; in the climate ethics literature, PPP theorists defend the claim that emitters should compensate those harmed by their emissions. However, we think this claim should be justified on the basis of the desirability of internalizing the externality. Doing so suggests that PPP is actually part of a broader project. If this is right, for any given externality, the best way to make it incentive-compatible is to introduce incentives with the same valence as the type of externality; if causing negative externalities, one should pay and, if causing positive externalities, one should be rewarded. At a first approximation, these should scale with the size of the negative and positive externality generated. The harms and benefits from these externalities are, we will argue in section 3, unearned but caused by the agent who is externalizing them. ${ }^{13}$

One of our key contributions follows from these intuitions. If (at least some) of those affected by positive externalities do not deserve those gains, then it is appropriate to use those resources to reward anyone who generates those positive externalities. They were lucky to receive them, but society would benefit more if the resources were used to align incentives in such a way that those who generate positive externalities gain from doing so, exactly in parallel to the claim that society would benefit if those who generate negative externalities paid for doing so. It is worth emphasizing that these intuitions may well be driven by luck egalitarian considerations (or at least luck-sensitive distributional ethics we are not committed here to egalitarianism as the shape or pattern of justice). We are not trying to punish - in the moral sense of the word - those who

\footnotetext{
${ }^{13}$ There is an important caveat to this claim. One of our contributions is suggesting that, some who benefit from positive externalities do earn their positive externalities, due to active strategies that take advantage of these externalities and contributing to overall social benefit, cf. section 3 .
} 
generate the negative externality; nor are we trying to punish anyone who gains from a positive externality. Instead, the idea is to align incentives in general so that, over the long term, society overall benefits from it being more expensive to generate negative externalities and more valuable to generate positive externalities.

A first reason for accepting our claims over, say, BPP is that an account that assesses gains and losses symmetrically has virtues in terms of simplicity and broader applicability. A theory that rewards positive externalities while penalizing negative externalities is conceptually simpler than one that assesses them asymmetrically. Indeed, the same logic operates throughout: a net winner is simply one that experiences a net 'negative loss'. The corresponding transfers are the same as for a net loser (i.e. they occur between emitters and the affected) but in reverse. ${ }^{14}$ Also, the concept has greater applicability because it applies to the broader class of cases with mixed externalities. For instance, it can handle cases where the negative externalities are smaller than the positive externalities or, at the limit, where one type of externality is absent. Another way of framing this advantage over alternatives is that thinking of having both transfers for this path via the emitters is didactic, in the sense that it draws attention to the conjunction of two externalities.

Second, from a social point of view, we should reward those who generate positive externalities in line with their contributions to society. Many gains to society, such as knowledge and innovation, are not sufficiently rewarded, which sends the wrong signals about how we want society to develop. In particular, there are familiar theoretical reasons to expect under-provision of public goods and over-provision of public bads. This fits into a broader background picture of internalizing all externalities, even in a case like climate change, where the (small) positive externalities are coupled with (far larger) negative externalities. ${ }^{15}$ Systematically internalizing both positive and negative externalities is of value. Also, we think that these externalities should be addressed through transfers that are directed towards the agents who created the externalities, in order for the resources to be used to generate those incentives. It is easy for intuitions about the very sizeable negative externalities of climate change to dominate our judgment to the point where we neglect the positive externalities. However, addressing only the negative externalities does not suffice to address the whole picture.

For many utilitarians, efficient incentivization of externalities (i.e. encouraging positive externalities and disincentivizing negative externalities) is morally justifiable in and of itself; we want our policies to lead people to be motivated to act prosocially. A secondary reason to internalize externalities is that it leads people to more explicitly recognize and weigh costs and benefits that are easily ignored when externalized. However, our account goes beyond merely advocating the theoretically appropriate internalization of externalities to arguments regarding the direction of these transfers. The common intuition that you should clean up

\footnotetext{
${ }^{14}$ In cases with mixed externalities, any transfers which effectively run from the net winners to the net losers via the emitters are epiphenomenal; they arise from the more fundamental points that there are transfers from two different types of externalities.

${ }^{15}$ Furthermore, if considering which externalities to prioritize in policymaking, there is a principled reason to consider climate externalities before other externalities: they may be the largest (Stern 2008).
} 
your own messes can be cashed out as introducing directed transfers. We believe that such transfers apply also in the case of positive externalities. This contrasts with a standard economic position, whereby the revenues from a Pigouvian tax need not be used to address the source of externalities, but instead should be used for whatever is most socially beneficial.

One objection to our account is that the emitters may no longer exist at the time of reparation. This is often a way of motivating BPP. However, we believe that we can meaningfully think of collectives like countries and firms as being the subject of significant responsibilities and continuity. First of all, appealing to countries is plausible because a significant amount of emissions can be traced back to countries (Moss and Kath 2019); indeed, significant proportions can be traced back even to individual firms (Heede 2014; Frumhoff et al. 2015; Shue 2017). Second, appealing to countries is also how international negotiations are structured, and we think that this has significant practical importance. Finally, we think that common sense takes groups of people to be subject to obligations and debts to society. Ultimately, the objection may also be moot because the set of cases we outline below can fully handle situations where emitters no longer exist.

Having laid out the guiding intuitions, we can now turn to more specific questions.

\section{Should net winners be left to enjoy their gains?}

In this section, we argue that there is a moral difference between passive and active net winners on both theoretical and practical grounds. We show that the difference justifies the claim that there should be transfers from passive net winners but not from active net winners. In other words, we think the former should not be allowed to enjoy their gains, whereas the latter should.

Why might one think that there is a moral difference such that the passive gains should or morally could be subject to transfers? We make two arguments. The first is that passive winners should transfer their gains because they did not earn or deserve them on the basis of active policies (subsection 3.1). The second is that, as a practical matter, to keep the incentives for active policies in response to climate change while being unconcerned about incentives for passive winnings - we can justify retaining the former profits while distributing the others (subsection 3.2).

\subsection{Active policies and desert}

Adaptation to climate change is an important pillar of climate policy, and it can involve changing practices, such as agricultural activities at the farm level or at the national scale. A first argument for the claim that there is a moral difference between active and passive net winners is that the active net winners have (actively) changed their relevant practices in order to benefit from climate change. This type of argument appeals to a certain type of libertarian or classically liberal political theory. In that respect, we believe that it results from one of the most prima facie unfriendly background positions to the significant redistribution we advocate.

By engaging in active measures, this argument goes, active winners have earned or deserve those gains. In contrast, the passive winners have not responded to climate change, and therefore have no desert basis for their winnings. This is endorsed in 'desert-based justice', a theory whereby agents deserve rewards 
('deserts') given 'desert bases' that are appropriately both the agents' responsibility and relevant to the reward (Olsaretti 2008; Brouwer and Mulligan 2019). In this context, the agents are the active net winners, their deserts are their climate gains and the desert basis is their active policies taking advantage of changing climatic conditions. In contrast, it looks like passive net winners do not have any desert basis for their climate enhanced gains. ${ }^{16}$

The distinction is thus between those who actively respond to climate change and those who do not - and therefore would act the same in the counterfactual world without climate change. The theory provides a principled way of drawing the moral difference between these active and passive categories. The active net winners could be responding to climate change directly, by entering markets where positive climate externalities apply, or indirectly, by entering markets to meet demand for climaterelated products or services where negative climate externalities threaten. In contrast, passive net winners would simply produce more or sell their products at higher prices due to shifts in market conditions for their existing products.

In practice, one may find it difficult to disentangle passive gains and those resulting from an active change in the course of action, but morally there is a significant difference and conceptually there is a clear distinction. As a suggestion of how one could operationalize this distinction, we propose three categories of actions that businesses could take to gain from climate change: (i) changes in prices and quantities supplied in response to demand or supply shifts; (ii) entering markets that have become profitable as market conditions evolve due to a changing climate; and (iii) developing innovative products to adapt to or mitigate climate change. Our opinion is that a category (i) change is a much less meaningful change in course of action than the other two: one could say it is a 'quantitative' change, as opposed to the other two, which can be deemed 'qualitative' in nature. Also, it is noteworthy that (ii) and (iii) do not require one's prior activity to be affected by climate change, so that these actions differ more explicitly from the status quo. Finally, setting the threshold for what is active between (i) and (ii) has the added advantage of greater observability.

In summary, on conventional versions of desert theories of justice, the benefits which accrue to those who (primarily) take active measures are more plausibly earned than those who (primarily) benefit passively (Olsaretti 2008). However, not only can we justify the active/passive distinction theoretically, we can also justify it by appealing to incentives.

\subsection{Incentives}

As one intention of this proposal is to align incentives, one argument for distinguishing between the active and passive beneficiaries of climate change is

\footnotetext{
${ }^{16}$ One could argue that the difference between active and passive winners could simply be that active winners are better informed and, thus, better able to respond to the changing climate. We thank Marc Fleurbaey for this observation. There are at least two ways to counter this objection. The libertarian answer retorts that individuals are responsible for their information-gathering as much as they are for their actions (for instance, their credence is equally likely that the action or gathering information will make a moral difference, cf. Mintz-Woo 2017). A more nuanced answer consists in pointing out the qualitative differences in the responses to climate change one might take, as we do by singling out behaviours (i)-(iii) below.
} 
motivated by incentives that we believe has been missed by standard BPP theorists. BPP, when not including our distinction between active and passive beneficiaries, would have massively counterproductive implications if adopted as policy. It is not a sensible policy to undermine incentives for developing products and services which address climate problems. Yet this is precisely what the standard BPP view would entail: it would require the corresponding gains to be disgorged to those harmed by climate change. As climate change advances, we will need more solutions for climate adaptation, not fewer.

As an example, consider the developer of an innovative solution to help populations better cope with the increase in global temperature. To allay distributional concerns, suppose that this innovation is cheap and effective, so that many can have access to it, regardless of wealth. Clearly, the developer of this climate solution benefits from the new climate. Also, we surmise that this is a clear case of an 'active' net winner, since they are responding to the climate demand. Nevertheless, the standard BPP view would require the disgorgement of all corresponding profits. This would eliminate any incentive to develop such solutions. By contrast, our account would preserve such incentives.

Here we see an important difference between passive and active winners from climate change. The behaviour of passive winners, whether via positive or negative externalities, does not need to be incentivized since, by definition, they would pursue the same policies regardless of climate change. So we would expect that they would be profitable (or at least would take themselves to be) regardless of climate change and regardless of the extra demand that accrues because of climate change. In contrast, the actions taken by active winners do need to be incentivized because, otherwise, they would not pursue the active policies that would be involved in, inter alia, responding to shifts in demand or production driven by climate change. ${ }^{17}$

The upshot of the discussion in these subsections is that there are two arguments for the claim that passive net winners, unlike active net winners, owe something to someone. The first depends on a certain type of desert-based theory; the second appeals to the incentives involved in rejecting our distinction. Note that we need not take a stand on the extent of the obligation, just that it arises in light of their status as passive net winners and that it has a relationship to the amount of their net winnings. The next question is where the gains that we argue are subject to permissible redistribution should be directed.

\section{To whom are net winners indebted?}

In the previous section, we argued for our first claim: climate net winners are not entitled to keep their passive gains. In this section, we argue for our second claim: that climate winners owe their passive gains to the emitters, not to the climate losers directly.

\footnotetext{
${ }^{17}$ Note that this proposal is consistent with the claim that active climate winners might lose the gains associated with their active status either (i) after some time or (ii) in some decreasing manner over time. Our claims just require that this differential incentive is needed for the initial actions in response to climate change.
} 
Our main claim is that, whenever possible, emitters should fully compensate the harm their emissions cause and, provided they do so, should be rewarded for the positive effects their emissions generate - that is, the PPTR Principle. This claim is chiefly motivated by economic efficiency, which is brought about when all actors internalize all externalities attached to their activities. ${ }^{18}$ Climate change is thus a special case of a broader set of market failures, albeit perhaps the largest one (Stern 2008).

When this ideal case cannot be achieved, we appeal to a concept we call a hierarchy of claims. This hierarchy holds that there is priority in fully redressing the losses of the harmed, which is the responsibility of emitters; another though secondary - obligation is for net winners to transfer their passive gains to emitters. In fact, this latter obligation only applies should emitters abide by their duty to compensate the harmed.

Our position is an intermediate one between, on the one hand, the stance that economic efficiency should rule above all, leading to fully symmetric treatment of gains and losses and, on the other hand, the commonly held view that punishes emitters by insisting that they compensate the harmed yet denies them the rewards for the social benefits their emissions generate. As mentioned, our position leads to the internalization of all externalities by emitters in the ideal case - but not in some non-ideal cases, as we will show - but has the palatable feature of recommending compensating the harmed first and foremost, thus generating more intuitive outcomes than a purely symmetric treatment.

In practice, however, the ideal situation of solvent and willing emitters may actually be an uncommon case. ${ }^{19}$ Of course, we believe that our proposal should be legislated such that any 'unwillingness' is subject to legal or criminal redress. However, it is worth distinguishing between three morally relevant non-ideal cases, depending on whether emitters are insolvent, unwilling to compensate climate harm, or no longer in existence, in reverse order:

1. Emitters no longer exist.

2. Emitters are present but unwilling to fully compensate the negative externality.

3. Emitters are present but unable to fully compensate the negative externality. The difference with Case 2 is motivated by the fact that emitters are making every effort to repair the harm they have caused. ${ }^{20}$

In none of the three cases are climate victims fully compensated by emitters. Therefore, one must ask whether the remaining transfers involving emitters in the ideal case - the transfers from climate winners to emitters - should still be upheld.

Clearly, in Case 1, whether winners should transfer gains to emitters is a moot point: there are no emitters to reward. However, this does not mean that climate winners are entitled to keep their gains. In fact, we argue the opposite. The mere

\footnotetext{
${ }^{18}$ Note that focusing on climate harm alone, by arguing against transfers from winners to emitters, would warp incentives and induce too little pollution compared with the efficient outcome.

${ }^{19} \mathrm{We}$ thank two anonymous reviewers for stressing this point.

${ }^{20}$ Although distinguishing between Case 2 and Case 3 may be difficult in practice, the distinction is morally relevant.
} 
disappearance of the emitters does not suddenly make the winners' (passive) gains legitimate. It simply means that the primary recipients of those transferred gains are no longer around. Yet, to the extent that there is uncompensated harm, we argue that the climate losers are natural ('secondary') recipients of the winners' gains. Therefore, in the absence of emitters, we claim that passive climate winners should transfer their gains to the harmed. ${ }^{21}$

In Case 2, where emitters are present but unwilling to fully compensate the harmed, we argue that the unwillingness of emitters to take part in the compensation scheme excludes them from receiving any transfers from climate winners. Indeed, it is our view that, by not compensating the harmed, the emitters have implicitly forfeited their part in the scheme. We are then back to Case 1 as far as transfers are concerned: passive winners should transfer their climate gains to the harmed.

Notice that a view focused purely on incentives, with no consideration of corrective justice, would yield different recommendations in Case 1 and in Case 2. From an ex post viewpoint, if emitters refuse to obey the rules of the transfer scheme - Case 2 - the incentives argument for transfers to and from the emitters vanishes. Hence, a purely incentives-focused view would simply be silent in Case 2, effectively recommending that net winners keep their gains.

Moreover, from an ex ante viewpoint, promising rewards to emitters who anticipate neglecting their duty to compensate the harmed would lead to warped incentives. This is because there are two externalities of opposite sign. Indeed, compared with a situation where both externalities are internalized, the scenario with no internalization may lead to emissions levels that are closer to the optimal ones than by internalizing only gains (as would be the case if, as in Case 2, emitters were still eligible for transfers from net winners). We illustrate this point with Figure 1, where the magnitude of the negative externality is much larger than that of the positive externality, as is the case for climate change. The only situation where this incentives argument does not hold is when the positive externality significantly outweighs the negative externality. There, rewarding only the positive externality yields better incentives than the scenario with no internalization (Figure 2). However, as far as we know, this situation does not arise in the case of climate change.

\footnotetext{
${ }^{21}$ It should be noted that climate winners are never liable for more than their passive climate gains. We assume that whatever wealth they may have outside of those climate gains has been acquired legitimately. Should it not be the case, any illegitimate earnings should be treated independently from the climate problem and are therefore beyond the scope of this article. Whether climate winners are liable for more than climate harm appeals to different principles. Should the winners' net climate gains exceed the harm to victims, what should happen to the surplus depends on how one weighs the institution of private property over social welfare. Indeed, a potential 'tertiary' recipient of transfers from climate winners could be society as a whole. If transferring the surplus - climate gains, net of compensatory transfers to the harmed - to society would yield huge social benefits, there is a case for requiring passive climate winners to transfer more of their gains, this time to society. If not, the social benefits may not be worth violating private property. In practice, determining whether such transfers are justified may be challenging (not least because of the regulatory uncertainty they could generate), but our arguments suggest that such transfers could be appropriate under some circumstances. Allowing this provision, we will assume that the size of the surplus is generally so small - if at all positive - that climate winners would be allowed to retain it.
} 


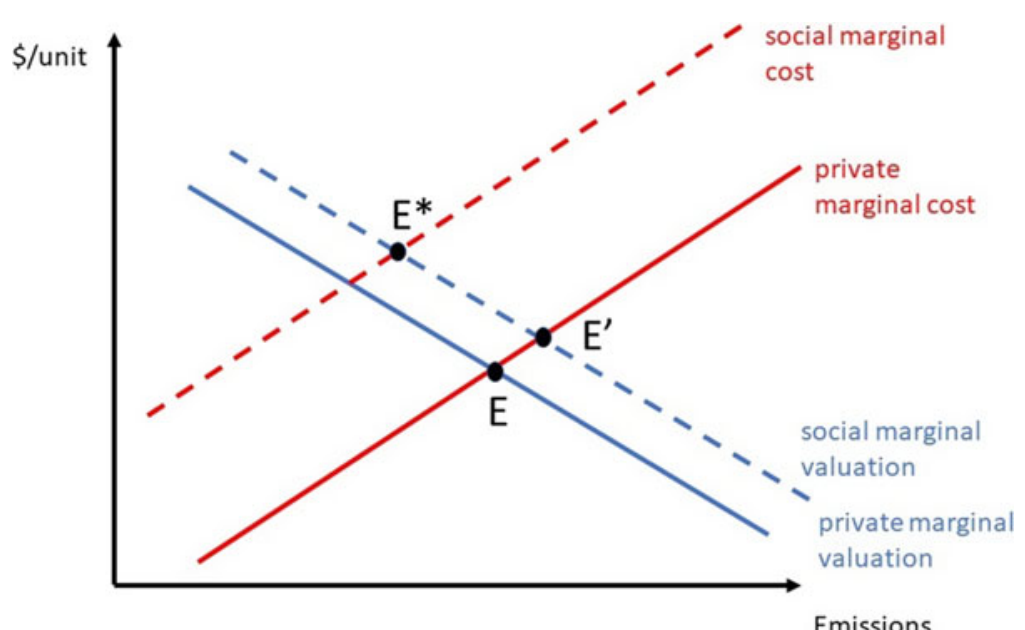

Figure 1. When the negative externality dominates the positive one, in the sense of $E^{*}$ being to the left of $E$, internalizing only gains leads to a further departure from the efficient emissions level: $E^{\prime}$ lies farther to the right of $E^{*}$ than $E$.

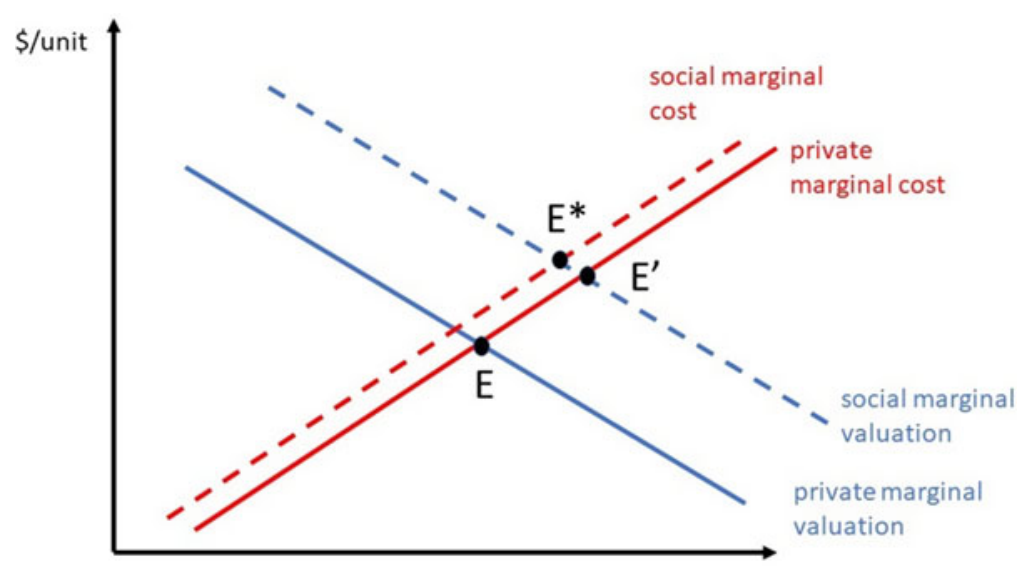

Emissions

Figure 2. When the positive externality is overwhelmingly large, the situation where only the positive externality is internalized incentivizes an emissions level (corresponding to point $E^{\prime}$ ) that is closer to efficient one, at $E^{*}$, than the business-as-usual scenario, at $E$.

Finally, turning to Case 3, the situation only differs from the ideal case in that emitters do not have deep enough pockets to shoulder the necessary compensation to the harmed. Compensating the harmed requires additional funds, such as those that the emitters can obtain from the passive winners. Passive winners would still owe their gains to emitters. In fact, a transfer from winners to emitters would help 
the latter to compensate the harmed. ${ }^{22}$ Equivalently, passive winners could transfer their gains to the harmed, in part or in full, up to the point where they are made whole. Whatever surplus remains, if any, should be transferred from passive winners to emitters.

This last case is related to the concept of 'joint and several liability' in tort law. ${ }^{23}$ According to this legal practice, a plaintiff can claim compensation for the full amount of an injury to any one of multiple tortfeasors. The tortfeasors who have paid the compensation may then be able to obtain contribution (i.e. partial reimbursement) from the remaining tortfeasors, according to their relative responsibility in the injury.

As was pointed out by Wright (1988), a corrective justice view of tort law requires that the cost of compensation is apportioned among the tortfeasors based on their comparative responsibility. However, redressing the harm of the injured plaintiff takes priority over realizing the appropriate transfers between other parties. Although net winners are by no means 'tortfeasors', this line of argument is similar in spirit to our notion of 'hierarchy of claims':

The caveat is critical. Under corrective justice theory, the tortiously injured plaintiff's claim against tortfeasors for full compensation has priority over the tortfeasor's claims against one another for apportionment of the cost of compensating the plaintiff. (Wright 1988: 1183)

A notable feature of joint and several liability is that the injured party is compensated directly by some tortfeasors, but indirectly compensated by others. The latter are those who partially reimburse the ones that have initially compensated the injured party for the full amount of the injury. This indirect path' occurs in our proposal also, whereby emitters fully compensate climate harm before receiving contribution from climate winners. Wright forcefully defends joint and several liability as opposed to joint and proportional liability where each tortfeasor is liable directly to the injured party, and only so, for partial compensation - arguing that having to locate and sue a single tortfeasor increases the likelihood that the injured party will be compensated.

\section{Policy implications}

Our proposal could be implemented in various ways. Ideally, the emitters of the world would compensate the harm caused to the climate victims of the world, and passive climate winners would compensate emitters regardless of national borders. If that is impossible, because emitters are unwilling or unable to compensate the harmed, or altogether absent, the various cases outlined above would apply. But the absence of a supranational power makes it doubtful

\footnotetext{
${ }^{22}$ Note that if the combined gains to emitters and climate winners are not enough to compensate the harmed, then it means that the corresponding emissions were socially harmful, in the sense of generating a net loss to society considered as whole.

${ }^{23} \mathrm{We}$ thank an anonymous reviewer for drawing our attention to the relevance of the concepts of tort law in this section.
} 
whether we could achieve these transfers at a disaggregated level. It is therefore prudent to consider a smaller scale at which to implement the proposal.

Up until now, we have talked about emitters, the harmed, and winners in a general manner. For purposes of implementation, and for the purposes of illustration, we consider two scales at which to apply the principle: between sectors of a national economy (subsection 5.1), and between states or provinces within a federal nation (subsection 5.2). For concreteness, we discuss Canada as a potential site of implementation. Canada has several characteristics which make it an interesting case: positively, it may be a politically palatable location for such policy experiments; negatively, it may be a net winner from climate change so restricting our scope to this particular country would be nonrepresentative for world policy. A side effect of Canada being a net winner would be that there would be a built-in constituency for such a policy; emitters could benefit from a Canada-only version of this policy.

\subsection{Sectors of the economy}

As mentioned in section 2, the likely climate winners can be most easily identified by sectors of activity within a population: for instance, evidence suggests the agricultural and tourism sectors in northern countries stand to gain from longer warm seasons. It therefore seems natural to identify those sectors that would have the duty to reward emitters.

A climate policy based on the concept of hierarchy of claims would require revenues from a carbon tax, say, to be aimed first and foremost at compensating the victims. ${ }^{24}$ Should these revenues not suffice to make victims whole, a supplementary tax, such as a corporate tax on those winning sectors, could be levied to further compensate climate victims. ${ }^{25}$ Should revenues from the carbon tax prove sufficient, those of the supplementary corporate tax would accrue to the emitters.

From a practical standpoint, one can envision ways to make these future outlays relatively predictable despite the uncertain nature of the future climate. One such possibility would be to compute climate gains based on climate trends (which can be predicted with reasonable accuracy in the short-to-medium run) rather than on given realizations (which cannot). Such trends are made available - although they could still be refined and, ideally, converted to monetary terms - by reputable institutions like the IPCC.

Moreover, from an efficiency standpoint, focusing on climate trends does not weaken incentives for emitters because efficiency requires them to consider the expected marginal harm of their emissions in their decision to emit. Furthermore, such an approach would have the added benefit of encouraging information gathering about the realized impacts of climate change. ${ }^{26}$

\footnotetext{
${ }^{24}$ Whether the policy instrument is a carbon tax or something else is of little import. What matters is that it is a revenue-generating instrument that applies specifically to emitters. Carbon taxes can be defended normatively from common objections (Mintz-Woo et al. 2020; Mintz-Woo 2021).

${ }^{25}$ To be explicit, the supplemental tax would be a tax on profits, not on emissions.

${ }^{26}$ These points are discussed in sections 4 and 5 of Billette de Villemeur and Leroux (2019), along with discussions of possible institutional design.
} 
Although much easier to implement than an international agreement, a withincountry sectoral approach would suffer from the fact that we are using a withincountry instrument to try to address a global problem. As a result, transfers would only apply to the externalities within a single country or jurisdiction. If the mix of externalities within that country were non-representative, this policy could generate counterintuitive results. For instance, in a high-emitting country with disproportionately large positive externalities, this can lead to cases where transfers add up to a net reward to its fossil fuel industry, since within the country there are greater positive externalities than negative externalities (although, globally, the opposite is the case). Ideally, we would ultimately want the emitters of that country and, if need be, its winning sectors to compensate the harmed in other countries, addressing all the externalities as opposed to this artificial territorial limitation. The situation depicted is not a mere thought experiment. A country like Canada, with high emissions per capita and relatively low negative externalities from the changing climate - and, arguably, net winning sectors would most likely see its own harm covered by a relatively low carbon tax, meaning that Canadian emitters would have to internalize a relatively small fraction of the negative externalities they cause worldwide, since the policy would consider only domestic externalities whereas the bulk of negative externalities are global. These emitters would even be entitled to the gains of Canadian (passive) climate winners. However, note that this counterintuitive case arises neither from the concept of hierarchy of claims itself, nor from the structure of the policy, but from the fact that we have regionally constrained the policy's application whereas the externalities are global. ${ }^{27}$ This is why we turn next to federalism, which we believe can yield useful insights towards global policy.

\subsection{Provinces of a federal nation}

At the regional (e.g. state or provincial) level, one would first need to identify whether some regions are indeed net climate winners. This is less likely than at the sectoral level discussed above, but could happen if some regions were especially known for, say, their large agricultural sectors (e.g. the Canadian province Saskatchewan).

There is currently much debate about how revenue from carbon pricing should be recycled, notably in Canada. ${ }^{28}$ All the options put forth assume that revenues would remain within the provinces - albeit entirely for political reasons (Canada's Ecofiscal Commission 2016). In other words, transfers between provinces would be a significant departure from the current political debate. Because these transfers would account for compensation for negative externalities, the policy would be a sort of 'interprovincial climate liability' ${ }^{29}$

\footnotetext{
${ }^{27}$ Discussion of independent moral considerations for making the social cost of carbon global as opposed to national are discussed by Mintz-Woo (2018).

${ }^{28}$ There is broad agreement that optimal policy should include revenue recycling, however (Klenert et al. 2018).

${ }^{29}$ Billette de Villemeur and Leroux (2019) introduce and analyse the features of climate liabilities as an economic instrument.
} 
Because they are composed of regional governments, federal nations provide a small-scale laboratory of how international policies might play out. The two major differences are, of course, (1) that there is no supranational government to impose legislation on countries, whereas a federal government has substantial power over provinces or states; and (2) buy-in could be affected by the nationally specific mix of externalities (as pointed out in the previous subsection). Since a federal government has substantial power, what cannot work under federalism has little chance of being implemented at the international level. On the other hand, successes encountered with a federal nation may provide useful hints for what is possible on the international stage. Our view is that testing or implementing these policy proposals at regional scales is invaluable for determining their large-scale viability.

\section{Conclusion}

The climate ethics literature has broadly grappled with the polluter pays, beneficiary pays and ability to pay principles. While climate change is often thought of as a single net externality, it is more rarely considered as a constellation of externalities, some smaller and some larger, some positive and some negative, externalities which may have different types of justice associated with them. More specifically, we are unaware of cases where positive climate externalities are systematically discussed. We think that the type of externality matters and, in cases where there are a mix of positive and negative externalities, both the polluter and the beneficiary should pay, but to different degrees and to different subjects, resulting in the polluter pays, then receives (PPTR) principle. The concept of hierarchy of claims offers a novel way forward by building upon the PPP while incorporating aspects of BPP as well as introducing elements beyond any of these three dominant principles to produce the PPTR Principle. Because of this, the PPTR Principle is not reducible to any combination of the three principles. Furthermore, PPTR does not pertain only to the climate issue; these claims potentially apply to any setting with mixed externalities (and of course, more trivially to cases where the externalities are purely negative or positive).

If only for strategic reasons, a comprehensive picture of climate change requires acknowledging the fact that positive externalities may exist. Indeed, focusing solely on negative externalities gives fodder to climate sceptics of a certain stripe, who can reinterpret this as a (simple to disprove) general statement that all climate externalities are negative. By accounting fully for the existence of positive externalities, one avoids this weak starting position.

We take there to be a strong case for obligations to emitters from passive net winners. The possibly counterintuitive nature of this claim may be a result of a type of priority with respect to negative externalities and the harms done by emitting to the climate net losers. In fact, it is the very foundation of our concept of hierarchy of claims. Although we agree with this priority, we are open to a simpler account which takes both treatment and assessment symmetrically. Regardless, we also believe that theories of climate justice should 
be able to handle further complexity, one facet of which we have grappled with in this paper.

Contributions. JL conceived of the project. KMW coordinated the joint initial draft writing and reviewing and editing, with contributions from both JL and KMW at each stage.

Acknowledgements. We thank Nicolas Bonneton, Lara Buchak, Marc Fleurbaey, Brian Jabarian, Feriel Kandil, Stéphane Lucchini, Tom Parr, Avia Pasternak, Laura Siggelkow, Alain Trannoy, Stephen J White, Eduardo Zambrano for stimulating comments, as well as audiences at Aix-Marseille School of Economics, the Canadian Philosophical Association, a Philosophy, Politics \& Economics Meeting, a Rocky Mountain Ethics Conference (especially our commentator Blake Francis), and Princeton and Brown Universities. Very many thanks go to searching and well-considered comments from two anonymous reviewers.

Financial support. Thanks to support from the Princeton University Library Open Access Fund Program for making this publication open access.

Disclosure. The authors declare no other potential conflicts of interest.

\section{References}

Atkins J.S. 2018. Have you benefitted from carbon emissions? You may be a "morally objectionable free rider". Environmental Ethics 40, 283-296.

Billette de Villemeur E. and J. Leroux 2011. Sharing the cost of global warming. Scandinavian Journal of Economics 113, 758-783.

Billette de Villemeur E. and J. Leroux 2019. Tradable climate liabilities: a thought experiment. Ecological Economics 164, 106355.

Broome J. 2012. Climate Matters: Ethics in a Warming World. New York, NY: Norton.

Brouwer H. and T. Mulligan 2019. Why not be a desertist? Three arguments for desert and against luck egalitarianism. Philosophical Studies 176, 2271-2288.

Buckley R. 2015. Local-scale environmental impacts and management of tourism. In The Routledge Handbook of Tourism and Sustainability, ed. C.M. Hall, S. Gössling and D. Scott, 320-328. Abingdon: Routledge.

Burke M., S.M. Hsiang and E. Miguel 2015. Global non-linear effect of temperature on economic production. Nature 527, 235-239.

Butt D. 2014. 'A doctrine quite new and altogether untenable': defending the beneficiary pays principle. Journal of Applied Philosophy 31, 336-348.

Canada's Ecofiscal Commission 2016. Choose wisely: options and trade-offs in recycling carbon pricing revenues. Technical report, Canada's Ecofiscal Commission.

Caney S. 2005. Cosmopolitan justice, responsibility, and global climate change. Leiden Journal of International Law 18, 747-775.

Caney S. 2010. Climate change and the duties of the advantaged. Critical Review of International Social and Political Philosophy 13, 203-228.

Dellink R., E. Lanzi and J. Chateau 2019. The sectoral and regional economic consequences of climate change to 2060. Environmental and Resource Economics 72, 309-363.

Dennig, F., M.B. Budolfson, M. Fleurbaey, A. Siebert and R.H. Socolow 2015. Inequality, climate impacts on the future poor, and carbon prices. Proceedings of the National Academy of Sciences USA 112, 1582715832.

Fleurbaey M. and S. Zuber 2014. Discounting beyond utilitarianism. Economics: The Open-Access, OpenAssessment E-Journal 40, 1-43. http://www.economics-ejournal.org/economics/discussionpapers/2014-40.

Fleurbaey, M., M. Ferranna, M.B. Budolfson, F. Dennig, K. Mintz-Woo, R. Socolow, D. Spears and S. Zuber 2019. The social cost of carbon: valuing inequality, risk, and population for climate policy. The Monist 102, 84-109. 
Fossheim M., R. Primicerio, E. Johannesen, R.B. Ingvaldsen, M.M. Aschan and A.V. Dolgov 2015. Recent warming leads to a rapid borealization of fish communities in the Arctic. Nature Climate Change 5, 673-677.

Frumhoff P.C., R. Heede and N. Oreskes 2015. The climate responsibilities of industrial carbon producers. Climatic Change 132, 157-171.

Gardiner S.M. 2004. Ethics and global climate change. Ethics 114, 555-600.

Gardiner S. 2011. A Perfect Moral Storm: The Ethical Tragedy of Climate Change. Oxford: Oxford University Press.

Godard O. 2017. Global Climate Justice. Cheltenham: Edward Elgar.

Goodin R.E. and C. Barry 2014. Benefiting from the wrongdoing of others. Journal of Applied Philosophy 31, 363-376.

Gosseries A. and L.H. Meyer, eds. 2009. Intergenerational Justice. Oxford: Oxford University Press.

Gregory P.J. and B. Marshall 2012. Attribution of climate change: a methodology to estimate the potential contribution to increases in potato yield in Scotland since 1960. Global Change Biology 18, 1372-1388.

Heede R. 2014. Tracing anthropogenic carbon dioxide and methane emissions to fossil fuel and cement producers, 1854-2010. Climatic Change 122, 229-241.

IPCC 2014. Climate Change 2014: Synthesis Report. Contribution of Working Groups I, II and III to the Fifth Assessment Report of the Intergovernmental Panel on Climate Change. Geneva: IPCC.

Jaggard K.W., A. Qi and M.A. Semenov 2007. The impact of climate change on sugarbeet yield in the UK: 1976-2004. Journal of Agricultural Science 145, 367-310.

Jansen, T., S. Post, T. Kristiansen, G.J. Oskarsson, J. Boje, B.R. MacKenzie, M. Broberg and H. Siegstad 2016. Ocean warming expands habitat of a rich natural resource and benefits a national economy. Ecological Applications 26, 2021-2032.

Kelleher J.P. 2017. Pure time preference in intertemporal welfare economics. Economics and Philosophy 33, 441-473.

Kjesbu O.S., B. Bogstad, J.A. Devine, H. Gjøsæter, D. Howell, R.B. Ingvaldsen, R.D.M. Nash and J.E. Skjæraasen 2014. Synergies between climate and management for Atlantic cod fisheries at high latitudes. Proceedings of the National Academy of Sciences USA 111, 3478-3483.

Klenert D., L. Mattauch, E. Combet, O. Edenhofer, C. Hepburn, R. Rafaty and N. Stern 2018. Making carbon pricing work for citizens. Nature Climate Change 8, 669-677.

Mechler, R., E. Calliari, L.M. Bouwer et al. 2019. Science for loss and damage. Findings and propositions. In Loss and Damage from Climate Change: Concepts, Methods and Policy Options, ed. R. Mechler, L.M. Bouwer, T. Schinko, S. Surminski and J. Linnerooth-Bayer, 3-37. Cham: Springer.

Meyer L.H. 2013. Why historical emissions should count. Chicago Journal of International Law 13, 597-614.

Meyer L.H. and D. Roser 2012. The timing of benefits of climate policies: reconsidering the opportunity cost argument. Jahrbuch für Wissenschaft und Ethik 16, 179-213.

Mintz-Woo K. 2017. A new defence of probability discounting. In The Ethical Underpinnings of Climate Economics, ed. A. Walsh, S. Hormio and D. Purves, 87-102. Oxford: Routledge.

Mintz-Woo K. 2018. Two moral arguments for a global social cost of carbon. Ethics, Policy \& Environment 21, 60-63.

Mintz-Woo K. 2021. Will carbon taxes help address climate change? Les ateliers de l'éthique/The Ethics Forum 16, 24-34.

Mintz-Woo K., F. Dennig, H. Liu and T. Schinko 2020. Carbon pricing and covid-19. Climate Policy. doi: 10.1080/14693062.2020.1831432.

Moss J. and R. Kath 2019. Historical emissions and the carbon budget. Journal of Applied Philosophy 36, 268-289.

Nelson E.J., P. Kareiva, M. Ruckelshaus, K. Arkema, G. Geller, E. Girvetz, D. Goodrich, V. Matzek, M. Pinsky, W. Reid, M. Saunders, D. Semmens and H. Tallis 2013. Climate change's impact on key ecosystem services and the human well-being they support in the US. Frontiers in Ecology and the Environment 11, 483-493.

Olsaretti S. 2008. Justice, luck, and desert. In The Oxford Handbook of Political Theory, ed. J.S. Dryzek, B. Honig and A. Phillips. Oxford: Oxford University Press.

Page E.A. 2008. Distributing the burdens of climate change. Environmental Politics 17, 556-575.

Page E.A. and A. Pasternak 2014. Guest editor's introduction. Journal of Applied Philosophy 31, 331-335. 
Poloczanska E.S., C.J. Brown, W.J. Sydeman, W. Kiessling, D.S. Schoeman, P.J. Moore, K. Brander, J.F. Bruno, L.B. Buckley, M.T. Burrows, C.M. Duarte, B.S. Halpern, J. Holding, C.V. Kappel, M.I. O'Connor, J.M. Pandolfi, C. Parmesan, F. Schwing, S.A. Thompson and A.J. Richardson 2013. Global imprint of climate change on marine life. Nature Climate Change 3, 919-925.

Poortinga W., A. Spence, L. Whitmarsh, S. Capstick and N.F. Pidgeon, 2011. Uncertain climate: an investigation into public scepticism about anthropogenic climate change. Global Environmental Change 21, 1015-1024.

Rahmstorf, S. 2004. The climate sceptics. Potsdam Institute for Climate Impact Research. http://www.pikpotsdam.de/.

Shue H. 1993. Subsistence emissions and luxury emissions. Law \& Policy 15, 39-60.

Shue H. 2015. Historical responsibility, harm prohibition, and preservation requirement: Core practical convergence on climate change. Moral Philosophy and Politics 2, 1-26.

Shue H. 2017. Responsible for what? Carbon producer $\mathrm{CO}_{2}$ contributions and the energy transition. Climatic Change 144, 591-596.

Stern N. 2008. The economics of climate change. American Economic Review 98, 1-37.

Stroeve J., M. Serreze, S. Drobot, S. Gearheard, M. Holland, J. Maslanik, W. Meier and T. Scambos 2008. Arctic sea ice extent plummets in 2007. Eos, Transactions, American Geophysical Union 89, 13-20.

Tchebakova N.M., E.I. Parfenova, G.I. Lysanova and A.J. Soja 2011. Agroclimatic potential across central Siberia in an altered twenty-first century. Environmental Research Letters 6, 045207-12.

Vardoulakis S. and C. Heaviside 2012. Health Effects of Climate Change in the UK 2012: current evidence, recommendations and research gaps. Technical report, Public Health England. ISBN 978-0-85951-723-2. www.hpa.org.uk.

Wallimann-Helmer I., L.H. Meyer, K. Mintz-Woo, T. Schinko and O. Serdeczny 2018. The ethical challenges in the context of climate loss and damage. In Loss and Damage from Climate Change, ed. R. Mechler, L.M. Bouwer, T. Schinko, S. Surminski and J. Linnerooth-Bayer, 39-62. Cham: Springer.

Watts N., M. Amann, N. Arnell et al. 2018. The 2018 report of the Lancet Countdown on health and climate change: shaping the health of nations for centuries to come. The Lancet 392, 2479-2514. doi: 10.1016/S0140-6736(18)32594-7.

Wright R.W. 1988. Allocating liability among multiple responsible causes: a principled defense of joint and several liability for actual harm and risk exposure. U.C. Davis Law Review 21, 1141-1212.

Kian Mintz-Woo is a Lecturer at University College Cork and was previously a Postdoctoral Research Associate at Princeton University. His work covers climate ethics, economics and policy as well as methodological and metaethical issues. For his climate communications work, he was selected as a finalist for the 2020 Andrew Light Award for Public Philosophy. Website: http://research.ucc.ie/profiles/ A023/kian.mintz-woo@ucc.ie

Justin Leroux is Professor of Economics at HEC Montréal, Fellow at CIRANO and co-director of the Ethics and Economics group at the Centre de recherche en éthique (CRÉ). Using a normative approach, his research mainly focuses on the distributional issues brought about by externalities. Email: justin.leroux@hec.ca Website: https://sites.google.com/site/justinlerouxecon/

Cite this article: Mintz-Woo K and Leroux J (2021). What do climate change winners owe, and to whom?. Economics and Philosophy 37, 462-483. https://doi.org/10.1017/S0266267120000449 